\title{
INCLUSION AND IMPLEMENTATION OF THE DYNAMIC DIMENSION IN THE PROCESS OF STRENGTHENING RESILIENCE OF SOCIETY: THE CASE OF THE LONDON TERRORIST ATTACKS OF 2005 AND $2017^{1}$
}

\author{
Gleb V. Kotsur \\ Saint Petersburg State University, Saint Petersburg, Russian Federation
}

\begin{abstract}
Introduction. The ecological notion of resilience has been adopted by different Western theoretical approaches in a wide range of scientific fields from economics to political studies. Canadian ecologist C. Holling defines resilience as a measure of the persistence of systems and of their ability to absorb change and disturbance (dynamic part) and still maintain the same relationships between populations or state variable (static part). The aim of this article is to identify the role of the dynamic dimension in strengthening resilience of British society during the period between the two London terrorist attacks of 2005 and 2017. Methods. The methodology of the paper is based on the discourse analysis of the key British documents on public security and the Internet publications immediately after the tragedy. Considering the theoretical aspect, the author distinguishes 'the bouncing back' approach (emphasizing static dimension), 'complexity' (dynamic) and 'adaptive cycles' being a middle ground. Analysis. Analysis of the key British security documents has shown that the government policy on strengthening resilience failed as it was characterized by an excessive predominance of the static element over the dynamic one. However, during the crisis, the London society managed to respond through specific set of adaptation measures such as grassroots self-organization through social networks, strategies of normalization and the phenomenon of habituation. Results. Results of this paper can be summarized in the following points: D. Chandler's concept of 'complexity' has the significant potential for understanding the effectiveness of counterterrorism strategies and ensuring public security. Russia, also facing the threat of international terrorism, should take into account the negative experience of British colleagues and avoid underestimating the preventive dimension of strengthening resilience.

Key words: resilience, international terrorism, fight against terror, public security, international security, socio-ecological systems.

Citation. Kotsur G.V. Inclusion and Implementation of the Dynamic Dimension in the Process of Strengthening Resilience of Society: the Case of the London Terrorist Attacks of 2005 and 2017. Vestnik Volgogradskogo gosudarstvennogo universiteta. Seriya 4, Istoriya. Regionovedenie. Mezhdunarodnye otnosheniya [Science Journal of Volgograd State University. History. Area Studies. International Relations], 2018, vol. 23, no. 6, pp. 154-163. (in Russian). DOI: https://doi.org/10.15688/jvolsu4.2018.6.12
\end{abstract}

УДК 327.8

Дата поступления статьи: 19.12.2017

ББК 66.4(0)

Дата принятия статьи: 20.05.2018

\section{ПРОБЛЕМА ВКЛЮЧЕНИЯ И РЕАЛИЗАЦИИ ДИНАМИЧЕСКОГО ИЗМЕРЕНИЯ ПРИ УКРЕПЛЕНИИ СТРЕССОУСТОЙЧИВОСТИ ОБЩЕСТВА: НА ПРИМЕРЕ ЛОНДОНСКИХ ТЕРАКТОВ 2005 И 2017 ГОДОВ ${ }^{1}$}

\section{Глеб Владиславович Коцур}

Санкт-Петербургский государственный университет, г. Санкт-Петербург, Российская Федерация

Аннотация. В данной статье рассматривается концепция стрессоустойчивости, которая становится все более популярной в западном академическом дискурсе и активно задействуется в ключевых документах, 
посвященных обеспечению международной и национальной безопасности. Автор выявляет роль динамического измерения при укреплении стрессоустойчивости британского общества в период между двумя лондонскими терактами - 2005 и 2017 годов. Проводимые британским правительством мероприятия в этой области характеризовались избыточным преобладанием восстановительных мер над превентивными. Подобный подход продемонстрировал свою неэффективность на фоне постоянно изменяющихся форм системных вызовов, которые угрожают публичной безопасности. Дискурс-анализ свидетельств трагедии июня 2017 г. в Лондоне показал, что социальный субъект в этих условиях выработал свой специфический набор адаптации: низовая самоорганизация через социальные сети, стратегия нормализации и феномен привыкания / отстранения.

Ключевые слова: стрессоустойчивость, международный терроризм, борьба с террором, общественная безопасность, международная безопасность, социоэкологические системы.

Цитирование. Коцур Г. В. Проблема включения и реализации динамического измерения при укреплении стрессоустойчивости общества: на примере лондонских терактов 2005 и 2017 годов // Вестник Волгоградского государственного университета. Серия 4, История. Регионоведение. Международные отношения. 2018. - T. 23, № 6. -C. 154-163. - DOI: https://doi.org/10.15688/jvolsu4.2018.6.12

Введение. Термин «стрессоустойчивость», будучи прежде всего экологическим понятием, с 1990-х гг. начал активно использоваться и в сфере политических наук для описания способности субъекта противостоять шокам [5]. По мнению крупнейших исследователей в этой области Дж. Брассета, С. Крофта и Н. Воган-Вильямса, ценность данной категории для политологии и науки о международных отношений заключается в углублении референтного объекта безопасности, охватывая собой одновременно множественные практики, сферы публичного пространства, финансов, инфраструктуры и др. [6]. Во многом в связи с этим обстоятельством приходится констатировать растущий в геометрической прогрессии интерес к понятию со стороны академического сообщества, что выражается в резком увеличении количества публикаций по этой теме [13, p. 5]. С другой стороны, стрессоустойчивость и ее достижение становится лейтмотивом такого основополагающего внешнеполитического документа ЕC, как «Глобальная стратегия Европейского союза по внешней политике и политике безопасности» [18]. Более того, целый ряд стран Запада прибегают к данному термину, формируя свои стратегии для противодействия международному терроризму [15; 29; 31].

Важнейшей чертой стрессоустойчивости как сложной и комплексной концепции можно назвать противоречивое сочетание динамического и статического аспектов, предполагающее одновременно и сохранение ключевых параметров субъекта после шока, и его адаптацию к новым условиям после кри- зиса. Этот сугубо теоретический вопрос в практической сфере превращается в конкретные проблемы, когда государство стремится укрепить стрессоустойчивость общества, акцентируя свое внимание или преимущественно на реагировании / восстановлении, или на превентивных мерах. Вкупе с антагонизмом между спущенным сверху директивным модусом действия и низовым подходом, основанным на гражданской самоорганизации, данные противоречия могут нивелировать все позитивные эффекты использования концепции стрессоустойчивости для построения новых стратегий обеспечения общественной безопасности.

Целью данной статьи может считаться выявление роли динамического измерения при укреплении стрессоустойчивости британского общества в период между двумя лондонскими терактами. Для достижения подобной цели мы прежде всего выделим главные теоретические подходы в академических дебатах по стрессоустойчивости, касающиеся оси «сохранение - изменение». Затем необходимо соотнести меры, предпринимаемые для укрепления стрессоустойчивости британского общества против терроризма после первого теракта в лондонском метро 2005 г., с основополагающими параметрами кризиса, вызванного терактом 2017 года. Два данных примера представляются особенно показательными для рассмотрения, так как в Великобритании стрессоустойчивость стала всеобщим рефреном противодействия терроризму именно после взрывов в лондонском метро 2005 года. Детально проанализировав роль динамичес- 
кого (превентивного) измерения стрессоустойчивости в ключевых британских документах по обеспечению безопасности и противодействию терроризму, мы сопоставим правительственные меры с реальной ситуацией «на земле» во время июньского теракта 2017 г. в Лондоне. Разница между ними позволит определить степень динамичности комплексного субъекта, включающего и государство, и социум, и сравнить этот компонент с развитием самой международной системы, изменчивость которой может или превосходить эволюцию субъекта, или находиться в относительной синхронности с ним.

Методологическая база исследования и теоретические корни понятия «стрессоустойчивость». Само понятие стрессоустойчивости было сформулировано в 1970-е гг. канадским экологом К. Холлингом как показатель устойчивости системы и ее способности абсорбировать изменения и сбои. Противопоставляя новую концепцию традиционному пониманию стабильности, подразумевавшему лишь возвращение к прежнему состоянию равновесия после временного шока, К. Холлинг замечает, что именно качество стрессоустойчивости экологической системы позволяет сохранять существующую конфигурацию структуры в функционирующем состоянии $[19$, p. 14]. За последующие десятилетия термин осуществил активную экспансию в академическом сообществе, где ширина спектра его применения характеризуется использованием концепции в столь различных областях, как городское планирование, экономика и политология [5]. Сегодня обеспечение безопасности и развития во внешнеполитических и национальных доктринах целого ряда западных акторов формулируются именно через термин «стрессоустойчивость» $[15 ; 29 ; 31]$.

На примере социоэкологических систем, откуда понятие стрессоустойчивости было перенесено в политические науки, становится очевидно, что данный термин отражает как способность системы адаптироваться к изменениям, так и сохранять ее устойчивость перед лицом этих изменений, если они негативны. Внутри самой концепции и практик, производимых при ее воплощении в жизнь, заложен и динамический, и статический компонент [17].
Анализ теоретической базы позволяет выделить три принципиально отличающихся подхода при описании рассматриваемой оси. Сторонников первого похода объединяет тезис о преобладании статики над динамикой, а также понимание данного процесса через феномен «отскакивания назад» («bouncing back»), где элемент изменяемости ограничивается, почти исключительно, способностью системы возвращаться обратно к равновесию. Подобное видение во многом противоречило изначальному определению К. Холлинга. Однако на ранних этапах развития концепта в области изучения влияния экологических катастроф на систему стрессоустойчивость понималась как средство против системной уязвимости, которая, в свою очередь, определялась как неспособность противостоять изменениям [23, p. 418]. Поэтому противостоящий ей термин «стрессоустойчивость» осуществлял фокус на статическом аспекте для достижения компенсаторного эффекта. Не стоит недооценивать и этимологическую инерцию: английское слово «resilience» произошло от латинского «resilio», что значит «отскакивать, возвращаться обратно».

Разумеется, сегодня экологи не отрицают динамическую перспективу внутри данной концепции полностью. Французский исследователь Ж.-К. Гайлар пишет, что «идеальное устойчивое общество - это такой социум, который способен преодолеть ущерб... либо через удерживание того состояния, что было перед катастрофой, либо приняв незначительные изменения, либо чуть большие...» $[16$, p. 531]. Таким образом, хотя теоретики и осознают невозможность полного игнорирования динамической компоненты, в их моделях остается очевидный крен на сохранение параметров системы в ущерб необходимости изменений. Однако подобный подход, несмотря на его прежнюю популярность, сегодня подвергся сокрушительной критике: сторонники иных способов видения изменений называют его предоставляющим наименее комплексную картину взаимодействия субъекта и системы [11].

Представители второго подхода при рассмотрении интересующей нас проблематики опираются на термин «адаптивные циклы» самого К. Холлинга, суть которого изложена им 
в монографии «Панархия», где автор понятия стрессоустойчивости значительно модифицировал его исходный вид. Согласно К. Холлингу и его соавторам, любая социоэкологическая система постоянно чередует 4 фазы своего развития: коллапс (восстановление) - реорганизация - рост - консервация. Затем вновь следует коллапс и весь цикл начинается сначала [26]. Подобная схема демонстрирует более сложный подход к соотношению статики и динамики, где система находится в постоянном изменении, однако через повторение четырех одинаковых этапов. Несмотря на то что адаптивный цикл на сегодняшний день остается наиболее популярной рамкой исследования рассматриваемой нами темы, данное видение стрессоустойчивости также было встречено критикой. Один из авторов «Справочника Рутледж по стрессоустойчивости» Э. Хорнборг видит неразрешимые противоречия в применении теории адаптивных циклов именно к социоэкологическим системам, так как в подавляющем большинстве случаев развитие социальной ее части совпадает с экономическим ростом, когда природная компонента претерпевает значительные испытания (например, вырубка лесов) [21]. Приходится признать, что две части системы находятся в контрфазе, что делает невозможным выделение циклов вообще.

Наконец, принципиально иной, третий концептуальный подход был предложен Д. Чендлером с опорой на «комплексность» («complexity») как новую парадигму функционирования политико-социальных структур. Комплексная жизнь, по автору, находится в состоянии постоянного изменения, саморегуляции и не поддается линейному планированию [7]. В подобной онтологии на первый план выходит динамическая компонента, где устойчивость субъекта достигается за счет относительного соответствия его собственных и системных изменений. Сама концепция комплексности имеет много параллелей с теорией нашего знаменитого соотечественника И. Пригожина [1], который писал о взаимосвязи хаоса и порядка, что признается и самим британским автором [7, p. 22-23]. Более того, невозможно не упомянуть и синергетику как важную часть интеллектуального базиса понятия, ведь, по замечанию Д. Чендле- pa, комплексность не поддается линейному планированию и каузальности по причине несводимости свойств системы лишь к сумме ее частей. Другой видный теоретик стрессоустойчивости П. Бурбо солидаризируется со своим британским коллегой: «...стрессоустойчивость - это не неизменная характеристика общества или человека. Более того, она не подразумевает завершенности, процесс никогда не окончен: по сути, он все время в динамике... Стрессоустойчивость - это всегда вопрос той или иной степени; полный иммунитет к турбулентности и шокам не существует...» [5, p. 384].

Несмотря на отдельные преимущества и недостатки каждой из вышеуказанных теоретических моделей, определить степень их практической эффективности возможно лишь после рассмотрения конкретного примера. Для решения данной исследовательской задачи общей методологической рамкой выступит дискурс-анализ, с одной стороны, основополагающих британских документов по публичной безопасности 2005-2017 гг., с другой - интернет-источников сразу после трагедии. Подобный комбинированный подход поможет нам понять: статика или динамика превалирует в государственном подходепо построению стрессоустойчивости после первого теракта. Вслед за этим сопоставление вышеуказанных мер с реальными параметрами теракта 2017 г. позволит нам сделать вывод о степени их адекватности постоянно меняющимся системным угрозам. Обращение к публикациям интернетисточников, фиксирующим кризисный момент со свидетельствами очевидцев, поможет нам понять способы реагирования самого общества на трагедию и выявить уровень расхождения ситуации «на земле» с директивным государственным подходом.

Анализ. Для определения степени соответствия каждого из трех подходов реальности обратимся к процессу выстраивания стрессоустойчивого субъекта в Великобритании между терактами 2005 и 2017 годов. В стратегии национальной безопасности 2010 г. терроризм назван первым из четырех приоритетных угроз с активным использованием термина «стрессоустойчивость». Однако акцент на противодействии данному вызову сделан через элемент реагирования (в документе при- 
сутствует раздел «Response»). Превентивное измерение находит отражение через необходимость использования дипломатии, торговли и вообще всех необходимых средств, чтобы страны - источники терроризма перестали поставлять террористов в Европу [29]. В роли ключевого угрожающего фактора обозначена возможность получения «Аль-Каидой» химического, радиоактивного или иного оружия, что выглядит максимально оторванным от реальности на фоне средств проведения теракта (нож, грузовой автомобиль) ИГИЛ (террористическая организация, запрещенная на территории Российской Федерации) в 2017 году. В стратегии 2015 г. подобная возможность была учтена, но лишь в качестве реакции на уже произошедшее в Париже [25]. Более того, двое авторов «Справочника Рутледжа по стрессоустойчивости» подчеркнули, что во всех документах и последующих мероприятиях по укреплению устойчивости элемент «превентивности» всегда проигрывал по проработанности «реагированию» («Responce») [8].

После теракта 2005 г. в Великобритании была развернута целая сеть из низовых организаций, призванных укрепить гражданскую стрессоустойчивость. Наиболее заметным примером здесь может считаться «Локальный форум стрессоустойчивости», где превентивное измерение обозначено в качестве одного из приоритетов функционирования сети, однако анализ документа позволяет сделать вывод о слабой проработке данного аспекта на фоне явного акцента на восстановлении, которому посвящен отдельный раздел с четко прописанным планом действий [30]. Применительно к столичному региону «Форум» реализуется в виде программы «Подготовленный Лондон», конструктивная роль которой заключается, по большей части, в информировании жителей о возможных рисках (наводнениях, пожарах, инфекциях) и организации сборов на помощь пострадавшим. Однако возможности данной программы несопоставимы с той дестабилизацией, которую вносит теракт в жизнь мегаполиса. Поэтому неудивительно, что никаких свидетельств существенной позитивной роли «Форума» в день трагедии в 2017 г. обнаружить не удалось.

Похожими недостатками страдает и контртеррористическая стратегия «Противодей- ствие» («Contest») в редакции от 2009 года. В разделе, посвященном трансформациям новых форм терроризма, в качестве одного из ключевых выводов опрометчиво постулируется готовность противника использовать различные формы оружия - от радиоактивного до химического [10]. Подобные заявления, не имеющие ничего общего со средствами проведения диверсий в Европе 2015-2017 гг., не нивелируют, однако, полностью значимость стратегии. Часть «Готовность» («Prepare») полностью выполнена духе стрессоустойчивости, с замечанием, что террористические атаки не всегда можно предотвратить, но необходимо смягчить их последствия [10]. Авторы документа подчеркивают необходимость учета уроков 2005 г. и развития местных сетей противодействия террору. Вообще, 2 из 4 частей стратегии посвящены предотвращению будущих кризисов, то есть, динамическому аспекту, вопросы вызывает лишь качество анализа [10]. По большей части в них содержится транспонирование негативных существующих трендов в будущее и меры по их нейтрализации.

Исследователи, обращающие внимание на особенности воплощения документов подобного рода в реальность, также фокусируются на неудачах именно превентивных частей стратегий. Например, рассмотренное выше «Противодействие» от 2009 г. содержит комплекс мер по предупреждению будущих угроз и построению стрессоустойчивости через включение находящихся в зоне риска социальных групп и их интеграцию в британское общество, однако подобные меры, по оценкам экспертов, не увенчались успехом [2]. Более того, Дж. Коффи и П. Фасси указали на дискриминационность и элементарную невозможность сочетания мер по надзору и наблюдению со стороны государства с требованием низовых инициатив и гражданского самосознания [9]. Теоретики отмечают также в дискурсе власти две важные линии, направленные, с одной стороны, на сплочение общества и развитие гражданского самосознания, а с другой - на низовой взаимный контроль, что проявляется, например, в требовании указывать полиции на подозрительные объекты в публичных местах [28]. Еще раз отметим низкую продуктивность подобных мероприятий 
со стороны властей, ведь теракт 2017 г. был осуществлен не с помощью взрывательных смесей, но вполне конвенциональных средств (нож, автомобиль).

Для того чтобы обрисовать уровень несоответствия проводимых мероприятий требованиям динамичности системы, обратимся к свидетельствам очевидцев трагедии в Лондоне 2017 года. Особенность этой атаки заключалась в том, что она производилась с помощью обыкновенного грузового автомобиля, а затем ножей, что привело к 7 прямым жертвам, а 48 человек пришлось госпитализировать [22]. Изменение способа терактов означает, что национальные службы безопасности должны работать 24 часа 365 дней в году и следить за людьми, которые внешне никак не выделяются, а террористам достаточно преуспеть один раз и «они будут гарантированно преуспевать» [24]. Исследователи, специализирующиеся на изучении международного терроризма в его новой форме, основными игроками здесь называют террористические полугосударства вроде ИГИЛ или Боко харам, что позволяет говорить с определенными оговорками о так называемой новой волне террора: эти акторы используют другие методы, обладают иной структурой и модусом существования / действия, чем это ожидается составителями контртеррористических стратегий прошлого [20].

Публицисты отмечают также децентрализацию современных террористических структур, которые производят свои акции меньшего размера без грандиозного плана, как это было 11 сентября 2001 года. Отныне исполнители теракта сами решают, когда и как атаковать, это подлинно сетевая структура [3]. Производимые же после 2005 г. британским государством мероприятия были направлены, напротив, на обнаружение подозрительных предметов и выявление иерархизированных террористических структур.

Вместе с тем необходимо констатировать наличие динамической адаптации самого общественного субъекта в отрыве от учреждаемых сверху практик. Граждане уже не первый раз проявили солидарность и низовую самоорганизацию, прежде всего через соииальные сети [4]. На их базе активисты обеспечили как координирующую функцию для организации волонтерской помощи, так и предоставили открытую для любого человека площадку для публичного обсуждения произошедшего. Принципиально важно, что коммуникативные возможности социальных сетей проявились в многофункциональном ключе: согласовывающая роль в день трагедии оказалась дополнена миссией дискуссионного пространства уже после произошедшего, где именно социальные сети предоставили резервуар для выражения солидарности всех неравнодушных с лондонцами.

Более того, в данном случае символом устойчивости города стал бегущий с места теракта человек с кружкой алкогольного напитка, не пожелавший прервать свой досуг даже в столь экстремальной ситуации [27]. Последующий в качестве общественной реакции юмор впервые стал мощным барьером против ужаса террора сразу после трагедии. Стихийно зародившаяся в связи с этим идея состояла в том, чтобы попытаться вести себя после теракта так, будто его не было, то есть в своего рода стратегии нормализации. Заметим, что ученые, исследующие особенности массового сознания в социальной психологии, сходятся во мнении, что юмор - это мощный медиатор в групповой интеракции, который способствует укреплению связей между ее членами [14]. Кроме того, в случае бедствия он способен оказывать компенсаторное стабилизирующее воздействие на психику человека, создавая дистанцию между сознанием и событием, благодаря чему и становится возможной упомянутая выше нормализация поведения. Если одна из главнейших задач террористов заключалась в дестабилизации жизненного стиля лондонцев, то, показательно отказавшись корректировать его, жители адекватно сформировали свой ответ на вызов террора.

Еще более важным обстоятельством произошедшего может служить принципиально иная в эмоциональном плане реакция общества: очевидцы отмечают наличие привыкания людей к потрясениям, когда некоторые из них фиксировали у себя практически полное отсутствие эмоций [12]. Подобная защитная реакиия отстранения нуждается в детальном анализе: это может быть как позитивным признаком зрелости общества (отсут- 


\section{ПОЛИТИЧЕСКИЕ НАУКИ И РЕГИОНОВЕДЕНИЕ}

ствие паники), так и негативным проявлением социальной апатии. Представляется, что феномен отстранения напрямую взаимосвязан со стратегией нормализации, так как в обоих случаях в массовом сознании происходит дистанцирование от события для избегания травмирующего эффекта. Целая серия терактов последних лет в городах Европы устранила часть восприятия подобного события как внезапного, что не исключило полностью шок как общественную реакцию, но трансформировало характер его воздействия на сознание европейцев.

Таким образом, директивный государственный курс британского правительства по укреплению стрессоустойчивости общества характеризовался существенными проблемами по включению и реализации динамического аспекта, то есть превентивных мер. В свою очередь общество в условиях стремительно меняющихся форм вызовов публичной безопасности ответило стратегиями нормализации и отстранения, где с помощью координирующих возможностей социальных сетей жители проявили гражданскую самоорганизацию. В текущий момент невозможно сказать с определенностью, являются ли эти реакции ситуативным феноменом или они надолго станут общей матрицей для социального противодействия будущим угрозам.

Результаты. Итак, сопоставление мер, предпринимаемых для укрепления стрессоустойчивости британского общества против терроризма после первого теракта в лондонском метро 2005 г., с основополагающими параметрами кризиса, вызванного терактом 2017 г., позволяет сделать три комплекса выводов.

Во-первых, из всех рассмотренных теоретических подходов к изучению стрессоустойчивости именно концепция «комплексности» Д. Чендлера обладает наибольшим потенциалом для осмысления эффективности контртеррористических стратегий и обеспечения общественной безопасности.

Во-вторых, благодаря подобной аналитической линзе становится очевидно, что и стратегический британский государственный курс по укреплению стрессоустойчивости, и проводимые мероприятия характеризовались избыточным преобладанием статического элемента над динамическим, где изменение подменено реагированием и поисками нового равновесия. Более того, директивно спускаемая сверху политика в этой области оказалась в антагонистическом противоречии с низовым подходом, основанным на гражданской самоорганизации. Как следствие, данные меры не оказались эффективными в связи с перманентно динамичными и флюидными параметрами самой системы международной безопасности. Системный вызов заключался в принципиально иных формах проведения террористического акта, к чему государственные структуры оказались не готовы.

B-третьих, в одинаковой кризисной ситуации государство и общество, будучи тесно взаимосвязаны, активизировали тем не менее разные защитные механизмы. На фоне радикального несоответствия статико-динамических осей государственных мер и новых системных вызовов социальный субъект выработал свой специфический набор адаптации из низовой самоорганизации через социальные сети, стратегии нормализации и феномена привыкания / отстранения.

Представляется несомненным, что для обеспечения стрессоустойчивости общества в сфере публичной безопасности необходимо учитывать вышеуказанный фактор комплексности системы. Лишь уделяя больше внимания динамическому аспекту адаптации, можно реагировать на вызовы своевременным образом. В свою очередь, российское государство, также стоящее перед лицом угрозы международного терроризма, должно учесть негативный опыт британских коллег и избежать недооценки превентивного измерения. Более того, пример лондонского теракта в июне 2017 г. продемонстрировал, что без всестороннего взаимодействия с гражданским обществом, никакие стратегии противостояния шокам не могут быть полностью эффективными.

\section{ПРИМЕЧАНИЕ}

${ }^{1}$ Исследование выполнено за счет гранта Российского научного фонда (проект № 17-18-01110 «Концепция стрессоустойчивости (resilience) Европейского союза: артикуляция и ее последствия для России»). 


\section{СПИСОК ЛИТЕРАТУРЫ}

1. Пригожин, И. Порядок из хаоса. Новый диалог человека с природой / И. Пригожин, И. Стенгерс. - М. : Прогресс, 1986. - 432 с.

2. Aly, A. The policy response to home-grown terrorism: reconceptualising Prevent and Resilience as collective resistance / A. Aly // Journal of Policing, Intelligence and Counter Terrorism. - 2013. - Vol. 8, № 1. - P. 2-18.

3. Beauchamp, Z. The London attack is the new face of terrorism - and it's very hard to stop/Z. Beauchamp // Vox. -2017. - June 5.

4. Bennhold, K. London's New Normal: Resilient, Yes. But Not Entirely Intrepid / K. Bennhold // The New York Times. - 2017. - June 15.

5. Bourbeau, P. Resilience and international politics: premises, debates, agenda / P. Bourbeau // International Studies Review. - 2015. - Vol. 17, № 3. P. 374-395.

6. Brassett, J. Introduction: an agenda for resilience research in politics and international relations / J. Brassett, S. Croft, N. Vaughan-Williams // Politics. - 2013. - Vol. 33, № 4. - P. 221-228.

7. Chandler, D. Resilience: The governance of complexity / D. Chandler. - N. Y. : Routledge, 2014. $-268 \mathrm{p}$.

8. Chmutina, K. Managing disaster risk and resilience in the UK: Response vs. prevention in policy and practice / K. Chmutina, L. Bosher // Routledge Handbook of International Resilience: Policies, Theories and Practices / ed. by D. Chandler, J. Coaffee. Abingdon : Routledge, 2016. - P. 267-279.

9. Coaffee, J. Constructing resilience through security and surveillance: the politics, practices and tensions of security-driven resilience / J. Coafee, P. Fussey// Security Dialogue. - 2015. - Vol. 46, № 1. P. 86-105.

10. Contest: The United Kingdom's Strategy for Countering Terrorism // The UK Government. Electronic text data. - Mode of access: https:// www.gov.uk/government/uploads/system/uploads/ attachment data/file/97995/strategy-contest.pdf(date of access: 19.07.2017). - Title from screen.

11. Cretney, R. 'Bouncing back' to capitalism? Grass-roots autonomous activism in shaping discourses of resilience and transformation following disaster / R. Cretney, S. Bond // Resilience. - 2014. Vol. 2, № 1.- P. 18-31.

12. Dastagir, A. What does it mean if terrorism no longer terrorizes us? / A. Dastagir // The USA Today. 2017. - June 6.

13. Dunn Cavelty, M. Resilience and (in)security: practices, subjects, temporalities / M. Dunn Cavelty, M. Kaufmann, K. Søby Kristensen // Security Dialogue. - 2015. - Vol. 46, № 1. - P. 3-14.
14. Francis, L. E. Laughter, the best mediation: Humor as emotion management in interaction / L. E. Francis // Symbolic Interaction. - 1994. - Vol. 17, № 2. - P. 147-163.

15. French White Paper on Defense and National Security of 2013 // The Ministry of the Armed Forces of France. - Electronic text data. - Mode of access: https://www.google.ruurl?sa $=\mathrm{t} \& \mathrm{rct}=\mathrm{j} \& \mathrm{q}=\&$ esrc $=$ s\&source $=$ web\&cd $=1 \&$ ved $=0$ ahUKEwiyutjDwMLVAh WEOhQKHYVKArUQFggnMAA\&url=http $\% 3 \mathrm{~A} \% 2$ F\%2Fwww.defense.gouv.fr\% $\% 2$ Fcontent $\% 2$ Fdownload $\%$ 2F215253\%2F2394121\%2Ffile\%2FWhite\%2520pape r\%2520on\%2520defense $\% 2520 \% 25202013$.pdf\&usg=A FQjCNHCpoexTwXXXr4ov8Hpm3pIZu2LjA (date of access: 19.07.2017). - Title from screen.

16. Gaillard, J. C. Resilience of traditional societies in facing natural hazards / J. C. Gaillard // Disaster Prevention and Management: An International Journal. - 2007. - Vol. 16, № 4. - P. 522-544.

17. Gunderson, L. Adaptive management and adaptive governance in the everglades ecosystem / L. Gunderson, S. S. Light // Policy Sciences. - 2006. Vol. 39, № 4. - P. 323-334.

18. High Representative of the Union for Foreign Affairs and Security Policy. Shared Vision, Common Action: A Stronger Europe. A Global Strategy for the European Union's Foreign and Security Policy // European Union External Action Service. - Electronic text data. - Mode of access: http://eeas.europa.eu/ archives/docs/top_stories/pdf/eugs_review_web.pdf (date of access: 19.07.2017). - Title from screen.

19. Holling, C. S. Resilience and Stability of Ecological Systems / C. S. Holling // Annual Review of Ecology and Systematics. - 1973. - Vol. 4, № 1. - P. 1-23.

20. Honig, O. A Fifth Wave of Terrorism? The Emergence of Terrorist Semi-States / O. Honig, I. Yahel // Terrorism and Political Violence. - 2017. - June 9. P. 1-19.

21. Hornborg, A. Resilience, Power and Money: Limitations and Prospects of Systems Ecology in Envisaging a Sustainable World Economy/A. Hornborg // Routledge Handbook of International Resilience: Policies, Theories and Practices / ed. by D. Chandler, J. Coaffee. - Abingdon : Routledge, 2016. - P. 147-158.

22. London terror attack: what we know so far. Electronic text data. - Mode of access: https://www. theguardian.com/uk-news/2017/jun/04/london-attackswhat-we-know-so-far-london-bridge-borough-marketvauxhall (date of access: 19.07.2017). - Title from screen.

23. Manyena, B. Disaster resilience: a bounce back or bounce forward ability? / B. Manyena // Local Environment: The International Journal of Justice and Sustainability. - 2011. - Vol. 16, № 5. - P. 417-424.

24. Narasimhan, V. What does resilience mean after London terror attack? / V. Narasimhan // DailyO. 2017. - June 4. 
25. National Security Strategy and Strategic Defence and Security Review 2015. A Secure and Prosperous United Kingdom // The UK Government. Electronic text data. - Mode of access: https://www. gov.uk/government/publications/national-securitystrategy-and-strategic-defence-and-security-review2015 (date of access: 19.07.2017). - Title from screen.

26. Panarchy: understanding transformations in human and natural systems / ed. by C. S. Holling, L. H. Gunderson. - Washington : Island Press, 2002. $536 \mathrm{p}$.

27. Pickrell, R. Man Fleeing Terror Attack with Beer In Hand Becomes Symbol of London's Resilience / R. Pickrell // The Daily Caller. - 2017. - June 4.

28. Salerno, D. The politics of response to terror: the reshaping of community and immunity in the aftermath of 7 July 2005 London bombings / D. Salerno // Social Semiotics. - 2017. - Vol. 27, № 1. - P. 81-106.

29. The National Security Strategy of the United Kingdom: Security in an interdependent world // The UK Government. - Electronic text data. - Mode of access: https://www.gov.uk/government/uploads/ system/uploads/attachment_data/file/228539/7291.pdf (date of access: 19.07.2017). - Title from screen.

30. The Role of Local Resilience Forums: A reference document // The UK Government. Electronic text data. - Mode of access: https://www. gov.uk/government/publications/the-role-of-localresilience-forums-a-reference-document (date of access: 19.07.2017). - Title from screen.

31. White Paper on German Security Policy and the Future of the Bundeswehr // The Federal Ministry of Defense of the Federal Republic of Germany. Electronic text data. - Mode of access: https://www. google.ru/url? $\mathrm{sa}=\mathrm{t} \& \mathrm{rct}=\mathrm{j} \& \mathrm{q}=\& \mathrm{esrc}=\mathrm{s} \&$ source $=$ web\&cd $=3 \&$ ved $=2$ ahUKEwia - X66qHeAhWCBS wKHUiRAdkQFjACegQICBAC\&url $=\mathrm{https} \% 3 \mathrm{~A} \%$ 2F\%2Fwww.bundeswehr.de\%2Fresource\%2Fresource\% 2FMzEzNTM4MmUzMzMyMmUzMTM1MzMyZT M2MzIzMDMwMzAzMDMwMzAzMDY5NzE3MzM1 Njc2NDYyMzMyMDIwMjAyMDIw\%2F2016\% 2520White\%2520Paper.pdf\&usg=AOvVaw2_PhoY59 TZKfuAQbAEA8dZ (date of access: 19.07.2017). Title from screen.

\section{REFERENCES}

1. Prigozhin I., Stengers I. Poryadok iz khaosa. Novyy dialog cheloveka s prirodoy [Order out of Chaos: Man's New Dialogue with Nature]. Moscow, Progress Publ., 1986. 432 p.

2. Aly A. The policy response to home-grown terrorism: reconceptualising Prevent and Resilience as collective resistance. Journal of Policing, Intelligence and Counter Terrorism, 2013, vol. 8, no. 1, pp. 2-18.
3. Beauchamp Z. The London attack is the new face of terrorism - and it's very hard to stop. Vox, 2017, June 5.

4. Bennhold K. London's New Normal: Resilient, Yes. But Not Entirely Intrepid. The New York Times, 2017, June 15.

5. Bourbeau P. Resilience and international politics: premises, debates, agenda. International Studies Review, 2015, vol. 17, no. 3, pp. 374-395.

6. Brassett J., Croft S., Vaughan-Williams N. Introduction: an agenda for resilience research in politics and international relations. Politics, 2013, vol. 33, no. 4, pp. 221-228.

7. Chandler D. Resilience: The governance of complexity. New York, Routledge, 2014. 268 p.

8. Chmutina K., Bosher L. Managing disaster risk and resilience in the UK: Response vs. prevention in policy and practice. D. Chandler, J. Coaffee eds. Routledge Handbook of International Resilience: Policies, Theories and Practices. Abingdon, Routledge, 2016, pp. 267-279.

9. Coaffee J., Fussey P. Constructing resilience through security and surveillance: the politics, practices and tensions of security-driven resilience. Security Dialogue, 2015, vol. 46, no. 1, pp. 86-105.

10. Contest: The United Kingdom's Strategy for Countering Terrorism. The UK Government. URL: https:/www.gov.uk/government/uploads/system/ uploads/attachment_data/file/97995/strategycontest.pdf (accessed 19 July 2017).

11. Cretney R., Bond S. 'Bouncing back'to capitalism? Grass-roots autonomous activism in shaping discourses of resilience and transformation following disaster. Resilience, 2014, vol. 2, no. 1, pp. 18-31.

12. Dastagir A. What does it mean if terrorism no longer terrorizes us? The USA Today, 2017, June 6.

13. Dunn Cavelty M., Kaufmann M., Søby Kristensen K. Resilience and (in)security: practices, subjects, temporalities. Security Dialogue, 2015, vol. 46, no. 1, pp. 3-14.

14. Francis L.E. Laughter, the best mediation: Humor as emotion management in interaction. Symbolic Interaction, 1994, vol. 17, no. 2, pp. 147-163.

15. French White Paper on Defense and National Security of 2013. The Ministry of the Armed Forces of France. URL: https://www.google.ru/url?sa=t\&rct= $\mathrm{j} \& \mathrm{q}=\& \mathrm{esrc}=\mathrm{s} \& \mathrm{~s}$ our ce $=$ web \& $\mathrm{cd}=1 \& \mathrm{ved}=$ 0ahUKEwiyutjDwMLVAhWEOhQKHYVKA rUQFggnMAA\&url=http $\% 3 \mathrm{~A} \% 2 \mathrm{~F} \% 2 \mathrm{Fwww}$.defense. gouv.fr $\% 2$ Fcontent $\% 2$ Fdownload $\% 2$ F $215253 \%$ 2F $2394121 \% 2 \mathrm{~F}$ file $\% 2 \mathrm{FWhite} \% 2520$ paper\% 2520 on $\% 2520$ defense $\% 2520 \% 25202013$.pdf\&usg= AFQjCNHCpoexTwXXXr4ov8Hpm3pIZu2LjA (accessed 19 July 2017).

16. Gaillard J.C. Resilience of traditional societies in facing natural hazards. Disaster Prevention and 
Management: An International Journal, 2007, vol. 16, no. 4 , pp. $522-544$.

17. Gunderson L., Light S.S. Adaptive management and adaptive governance in the everglades ecosystem. Policy Sciences, 2006, vol. 39, no. 4, pp. 323-334.

18. High Representative of the Union for Foreign Affairs and Security Policy. Shared Vision, Common Action: A Stronger Europe. A Global Strategy for the European Union's Foreign and Security Policy. European Union External Action Service. URL: http:// eeas.europa.eu/archives/docs/top_stories/pdf/ eugs_review_web.pdf(accessed 19 July 2017).

19. Holling C.S. Resilience and Stability of Ecological Systems. Annual Review of Ecology and Systematics, 1973, vol. 4, no. 1, pp. 1-23.

20. Honig O., Yahel I. A Fifth Wave of Terrorism? The Emergence of Terrorist Semi-States. Terrorism and Political Violence, 2017, June 9, pp. 1-19.

21. Hornborg A. Resilience, Power and Money: Limitations and Prospects of Systems Ecology in Envisaging a Sustainable World Economy. D. Chandler, J. Coaffee eds. Routledge Handbook of International Resilience: Policies, Theories and Practices. Abingdon, Routledge, 2016, pp. 147-158.

22. London terror attack: what we know so far. URL: https://www.theguardian.com/uk-news/2017/jun/ 04/london-attacks-what-we-know-so-far-london-bridgeborough-market-vauxhall (accessed 19 July 2017).

23. Manyena B. Disaster resilience: a bounce back or bounce forward ability? Local Environment: The International Journal of Justice and Sustainability, 2011, vol. 16, no. 5, pp. 417-424.

24. Narasimhan V. What does resilience mean after London terror attack? DailyO, 2017, June 4.

25. National Security Strategy and Strategic Defence and Security Review 2015. A Secure and
Prosperous United Kingdom. The UK Government. URL: https:/www.gov.uk/government/publications/ national-security-strategy-and-strategic-defence-andsecurity-review-2015 (accessed 19 July 2017).

26. Holling C. S., Gunderson L. H., eds. Panarchy: understanding transformations in human and natural systems. Washington, Island Press, 2002. 536 p.

27. Pickrell R. Man Fleeing Terror Attack with Beer In Hand Becomes Symbol of London's Resilience. The Daily Caller, 2017, June 4.

28. Salerno D. The politics of response to terror: the reshaping of community and immunity in the aftermath of 7 July 2005 London bombings. Social Semiotics, 2017, vol. 27, no. 1, pp. 81-106.

29. The National Security Strategy of the United Kingdom: Security in an interdependent world. The UK Government. URL: https://www.gov.uk/ government/uploads/system/uploads/attachment_ data/file/228539/7291.pdf(accessed 19 July 2017).

30. The Role of Local Resilience Forums: A reference document. The UK Government. URL: https://www.gov.uk/government/publications/therole-of-local-resilience-forums-a-reference-document (accessed 19 July 2017).

31. White Paper on German Security Policy and the Future of the Bundeswehr. The Federal Ministry of Defense of the Federal Republic of Germany. URL: https://www.google.ru/url? sa=t\&rct=j\&q= \&esrc $=$ s\&source $=$ web\&cd $=3 \&$ ved $=2$ ahUKEwia_X66qHeAhWCBSwKHUiRAdkQFjACegQICBAC \&url $=$ https $\% 3 \mathrm{~A} \% 2 \mathrm{~F} \% 2 \mathrm{Fwww}$.bundeswehr.de $\%$ 2Fresource\%2Fresource\%2FMzEzNTM4MmUzMzMy MmUzMTM1MzMyZTM2MzIzMDMwMzAzMDMw MzAzMDY5NzE3MzM1Njc2NDYyMzMyMDIw MjAyMDIw\%2F2016\%2520White\%2520Paper.pdf \&usg=AOvVaw2_PhoY59TZKfuAQbAEA8dZ (accessed July 19, 2017).

\section{Information about the Author}

Gleb V. Kotsur, Master Student, Department of Theory and History of International Relations, Saint Petersburg State University, Smolnogo St., 1/3, 191060 Saint Petersburg, Russian Federation, glebk17@gmail.com, https://orcid.org/0000-0003-4079-264X

\section{Информация об авторе}

Глеб Владиславович Коцур, магистрант кафедры теории и истории международных отношений, Санкт-Петербургский государственный университет, ул. Смольного, 1/3, 191060 г. СанктПетербург, Российская Федерация, glebk17@gmail.com, https://orcid.org/0000-0003-4079-264X 